\title{
Teaching Renewable Energy Systems by Use of Simulation Software: Experience at Universities of Applied Sciences, in In-Service Training, and from International Know-How Transfer
}

\author{
Andreas Witzig ${ }^{1}$, Markus Prandini ${ }^{2}$, Andreas Wolf ${ }^{3}$, Lars Kunath ${ }^{3}$ \\ ${ }^{1}$ ICP Institute of Computational Physics, and ${ }^{2}$ Competence Center Asia Business, both at the \\ Zurich University of Applied Sciences, Winterthur, Switzerland \\ ${ }^{3}$ Vela Solaris AG, Stadthausstrasse $125, \mathrm{CH}-8400$ Winterthur, Switzerland
}

\begin{abstract}
Experience in using simulation software for teaching solar energy and heat pump applications are presented and discussed in this publication. The authors present suitable didactic concepts specifically developed for teaching renewable energy and energy efficiency topics.

Two main advantages of applying simulation software in solar education are identified:

1. simulation can provide an understanding of data that is otherwise not accessible (e.g. cumulated operating hours and number of starts of a heat pump depending on control strategy);

2. use of simulation software in teaching have a positive influence on the motivation and attitude of the students.

These benefits typically come with costs of some additional effort in lecture preparation.

Finally, different international teaching programs are discussed, in which simulation software currently plays a major role. It is analyzed how education programs might have to be adjusted for different cultures and industries.
\end{abstract}

Keywords: Renewable energy education, teaching solar systems, seamless learning, simulation software

\section{Scope and Introduction}

The scope of this work is professional education in renewable energy from in-service training to the technical-university level. It does not cover solar education to children or to the common public. Furthermore, this work has a special focus on the use of simulation software in teaching and is an update to previously described experiences (Witzig 2009). In all the described courses, the curriculum focusses on the renewable energy topics and the skills required by engineers, planners and consultants involved in solar energy system analysis and design. Reflections about teaching experience do not cover courses specifically on the usage of software or on software programming aspects.

It has been recognized early that computer simulation has a high potential to influence learning in science (e.g. Feurzeig 1999, Rutten 2012), many articles and books have been published about it and there was a controversial discussion about the effect of the use of simulation tools in education. Specific overview articles also summarize the use of simulation software in specialized fields of technology. Examples are health care (Cook 2011), chemical and process engineering (Edgar 2006) and unequivocal results exist for many other field. 


\section{General Observations}

Three main prerequisites strongly influence learning achievements:

3. The choice of the simulation software has to closely match the interests and abilities of the students. General purpose mathematical tools like Matlab/Simulink or Mathematica are only helpful in engineering courses at university level when separate courses on how to use the tools are offered in the curriculum.

4. Simulation tools have to be user-friendly. On the one hand, the "fun" factor is not to be underestimated: if students like to play around with the tool, they also learn more. On the other hand, user-friendliness is required in order that students are efficient in their assignment work.

5. Personal laptops have to be available to all students. Computer laboratories have been an option at times when students have not had their own laptops. However, the advantage of bringing the exercises into the student's work environment allows a new dimension of involvement and reduces the cost of providing access to simulation tools.

These necessary conditions may vary depending on application field and teaching institution.

The authors think that temporal change of these boundary conditions are sometimes underestimated in the above cited review articles. While institutions and topics are relatively stable, simulation software improves steadily in its user-friendliness. In comparison to the first two points, the availability of laptops as a third requirement has changed dramatically in recent years. Students carry a large amount of computing power with them and have the ability to install and use standard software without any support from the teacher or the IT department.

\section{Use of Simulation Software in Solar Education}

Historically, the first software used in university-level solar education was TRNSYS (Kandpal 2015, Bronman 1991). The usage of TRNSYS in solar education was limited to a small group of people in the beginning due to the lack of computers. The user experience was impaired by the text based scripting interface but improved with the introduction of the TRNSYS simulation studio.

A number of software packages have been established later on in parallel to TRNSYS, most of them with a simpler user interface and somewhat reduced functionality. Some of them have successfully been applied in teaching solar energy (e.g. free: RETscren, PVGIS; commercial: T*Sol, Polysun, PVSyst, Insel).

Simulation software programs used in general physics education (e.g. Stella, Berkley Madonna, EES, Matlab) are less suitable for solar energy teaching since they are more complex and have no built-in references to renewable energy systems. It has been found that the tools have to use the specific nomenclature of the solar business and as to offer special functionality imposed by industry standards. Recent didactic concepts confirm that the "seamless" integration into the well-known environment of the student strongly increases the learning success (Milrad 2013).

The authors have been active for many years with the Polysun simulation tool and used it in the first place in solar and renewable energy teaching Swiss Universities of applied sciences, secondly in non-academic inservice training and thirdly for courses related to big companies in conjunction to commercial projects. All the above mentioned software tools have primarily been developed for professional users and not for the classroom, except some minor adaptation for educational usage is in the licensing scheme. Therefore, the graphical user interfaces are optimized to be useful for the customer target group. For Polysun these are the planners and engineers in consulting companies. Both in-service training and undergraduate courses profit from this because it makes the courses more application oriented.

In the use for undergraduate or in-service teaching courses it has been proven to be particularly useful to visualize relationships that are not accessible to measurement or analytical calculations, as discussed in the following three examples: 
- While the characteristics of isolated components can be presented in lectures, it is a challenge to discuss the dynamic behavior of the hydraulic system. While governed by simple physical laws, the system performance is much more complex. Simulation software helps to let students investigate the operation of controllers and the placement of sensors. As shown in Figure 1, the Polysun simulation tool reveals the relevant details. Using trial and error or more systematic design methodology close to real planner's work, students use the software to "play around", investigate and optimize renewable energy systems.

- Yearly calculation results such as system efficiency, heat pump seasonal performance factors or cumulated operating hours and number of starts of a heat pump all strongly depend on the control strategy. With the use of a dynamic system simulation, these relationships become accessible for the teaching process and for exercises.

- Parametric studies with varying component characteristics and control strategies are another application area. Students have to learn to define an optimization target function and ask precise questions for optimization. Furthermore, the methodologies taught in renewable energy courses include the use of Excel as an analysis tool.

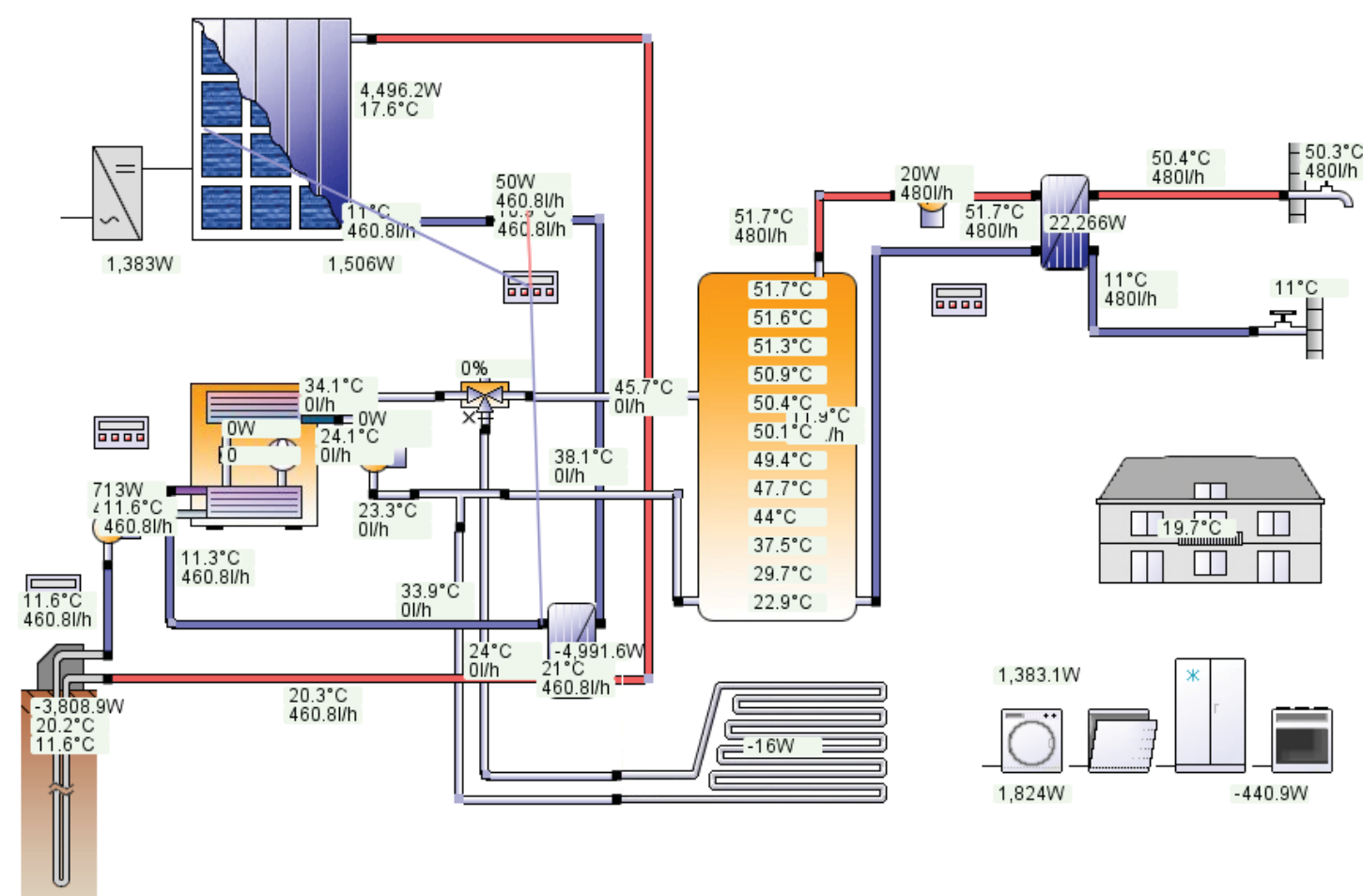

Figure 1: Polysun dynamic simulation allows to step into a certain time on a specific day of the year and follow the system behavior step by step on a short time scale. It allows students to recognize the details of the controllers, as for example in this application the controller (blue lines show connection to sensors, red lines show connection to the pump as an actuator). 


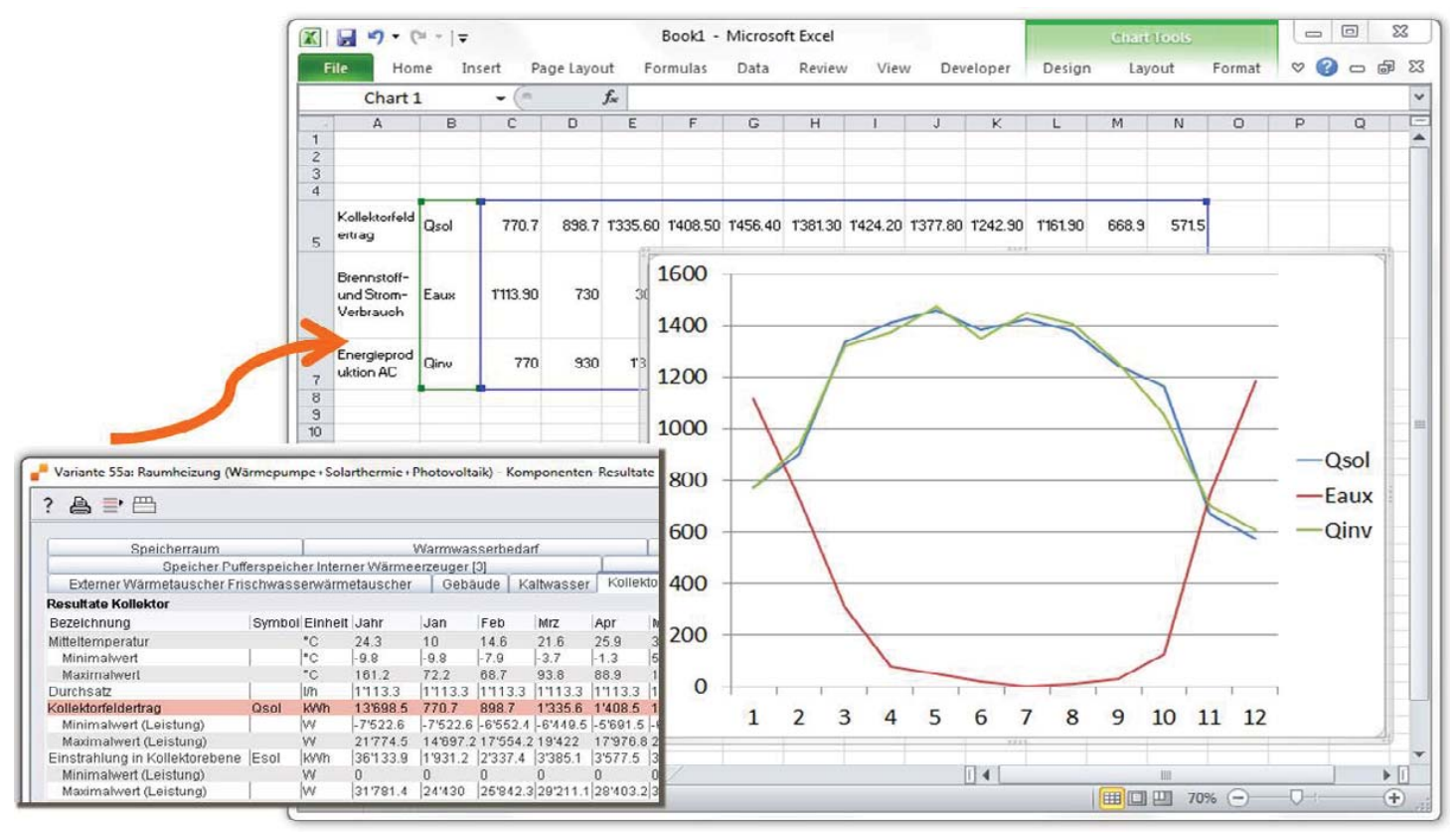

Figure 2: Simulation results can be manually or automatically transferred to other tools for advanced analysis and optimization. In this example it is shown how to transfer data to Excel.

Not least, the use of simulation software makes the renewable energy courses more attractive and increases the motivation and attitude of the students. It helps to position energy planners as high-tech consultants. Using a real-world planning tool provides a direct link to the work environment the students are likely to work in after graduation and allows showing how much impact good planning has on realistic projects and how much sense the future work will make.

While some bigger projects involve the creation of a curriculum (such as the examples reported in Section 6), the contents are typically encapsulated in smaller entities. The resulting teaching material can be used to enrich traditional solar energy or renewable energy courses in a similar manner as laboratory exercises as presented in Figure 3. It is important to convince teachers of traditional engineering topics to use examples from renewable energy systems to visualize general energy related topics. If material is provided in wellportioned entities and offered in a similar manner as experiments are in traditional engineering schools, the value of the teaching material increases and renewable energy topics have a higher chance to enter the general engineering curriculum. 


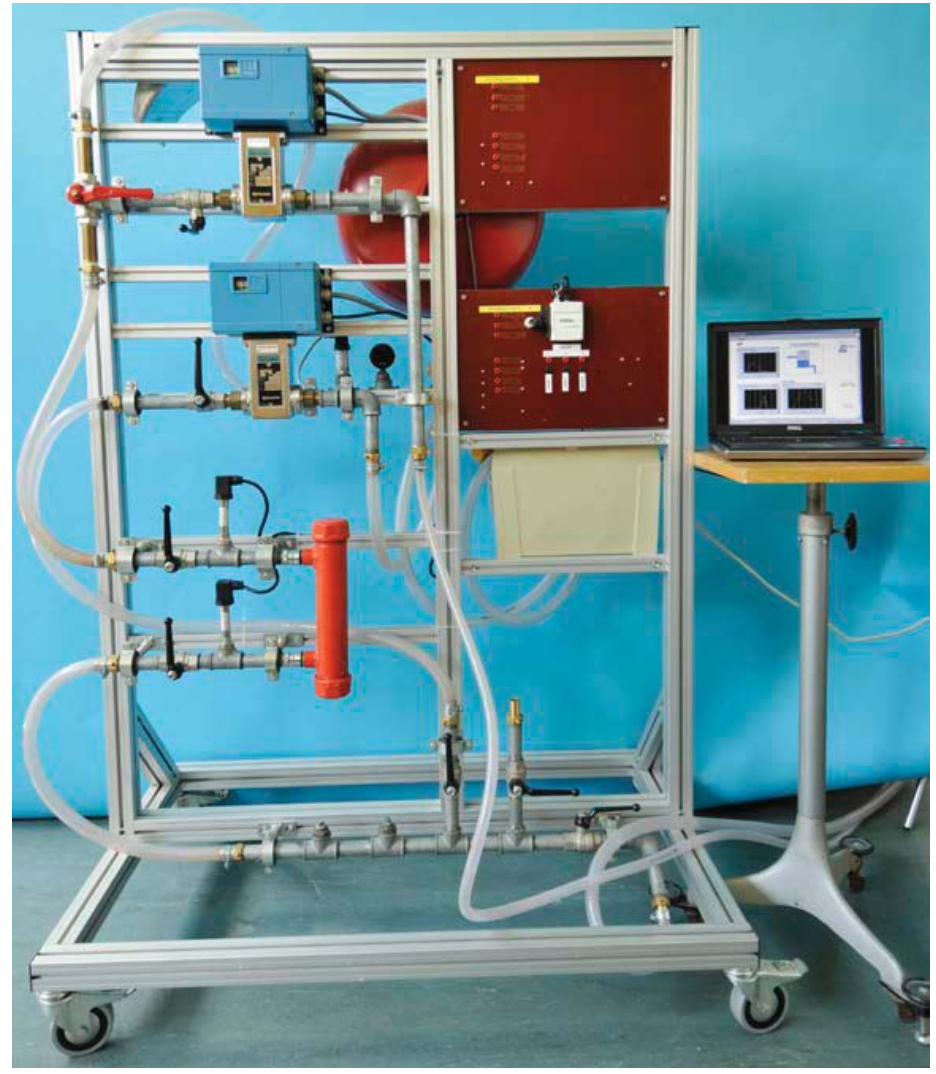

Figure 3: Example for a hardware exercise from the experiment collection at Zurich University of Applied Sciences. Teachers can choose from a large collection of hardware experiments with wellprepared exercises to enrich classroom work. The authors propose to offer renewable energy topics using simulation software in a similar manner like physics experiments.

\section{Recent Changes in the Solar Industry and in Solar Education}

Renewable energy engineering has become more comprehensive in the last few years. In modern decentralized energy systems it is common to combine different renewable energy sources such as solar collectors and ground source loops. Some time ago, solar thermal engineering has been a self-contained topic, mostly situated in the mechanical engineering curriculum at universities of applied sciences. Now the interaction between the different disciplines (photovoltaics - energy storage - solar thermal - heat pump ventilation and air conditioning) is addressed and in many engineering schools there are specific degree programs on energy and environment.

With the advance of the renewable energy industry, solar components have become more plug-and-play on the one hand, but renewable energy systems on the other hand have become more complex. The main expertise is therefore no longer in sizing and configuring solar components but in integrating the components into a system. Solar systems are often no longer strictly separated into solar thermal and photovoltaic systems. Hybrid systems and combination with heat pump and energy optimization controllers such as load shifting require new skills from planners and engineers. In consequence, it is required that students spend more time on understanding system dynamics and the proper functioning of controllers.

\section{Learning Success and Secondary Effects of Simulation Software in Solar Education}

Teaching courses using simulation software have to be supported by suitable didactic concepts, which need to cover classroom activities as well as computer homework (e.g. Rumsey 2000). In contrast to using video material in teaching, the application of simulation tools is very close to real "hands-on" activities. In socalled seamless learning, trainees study across boundaries such as location, time, analog/digital, and classroom/at home (Milrad 2013). Often, modern ICT technology is required to achieve a seamless learning 
context (Pillay 2006). We often teach expert technicians in a 1:1 screen sharing setting, which allows immerging into the work context of the trainees and using their everyday examples. Alternatively, we use traditional classroom teaching enriched with exercises using simulation tools. During simulation sessions, the teacher acts in the role of a coach and students are actively pursuing their design projects. Interpretation of simulation results and double-checking results with simple back-of-the-envelope calculations are typically pursued with rigor and an excellent mental awareness when the example is chosen from the trainee's everyday scope of duty.

Advantages when using simulation software and modern ICT technology for teaching:

- Students are activated. They have to take responsibility, make decisions and organize their work.

- Trainees can pick the topic that is relevant for them.

- Collaboration between students: they share their findings, help each other, and discuss their results.

- Progress in the exercise is visible to the teacher during class and easily measurable after class.

- Exceptionally high motivation, in particular for in-service and screen sharing training.

Challenges and risks:

- Preparation is key for teaching with simulation software. Exercises have to be formulated in detail and test runs are indispensable.

- The teacher has to be a proficient user of the software as well as have the essential skills in the area of expertise of the course participants.

Not least, there are excellent and important practical experiments in solar education. As much as the authors believe that computer simulation has a positive learning effect, they are convinced that laboratory exercises are also a necessary requirement for solar engineers and do not consider computer simulation as a substitute for them.

Simulation makes the system aspect accessible. It has been shown in the literature that effect size of use of simulation software in teaching is especially high if it is used for phenomena that are unobservable (Trey 2008). In the case of hybrid solar system simulation there is no alternative to numerical simulation for the analysis of the dynamic system behavior. Experience shows that students get puzzled by the large number of unknowns in hybrid systems and, in particular, that rules of thumbs do only apply to limited parameter ranges. Simulation software helps to reduce the number of unknowns by the definition of adequate default values. These simplifications are necessary for good didactical best practice. The authors have experienced that it is only at the very top of University-level engineering courses, one should confront students with the large uncertainty that lies behind every system simulation. Otherwise, the learning effect regarding renewable energy topics is compromised. At any time, one has to be aware that solar simulation is only a tool used in solar education. In other courses at the MSc or postgraduate level (that go beyond the scope of this article), it is good to go into detail on computational algorithms and discuss the influence of each default parameter.

\section{Teaching Experience Abroad}

Solar energy is a world-wide topic and solar engineering education is in many regions of the world a limiting factor in the energy transition. The authors have been involved in renewable energy teaching in Switzerland and the neighboring countries, mostly in conjunction with the simulation software Polysun. Some specific activities also cover the Scandinavian countries (Bales 2016, Andersen 2016), the Mediterranean area and specific projects in Egypt (Khayet 2014), China (Wolf 2016, Prandini 2016) and Kuwait (Al-Yaseen 2016). In many activities, the simulation software Polysun played a major role in overcoming translation challenges and to measure and ensure the proficiency level. 
Market development is very different in various regions. While in Germany, there was a strong growth in photovoltaics until 2013 with the installed photovoltaic area almost doubling several years in a row, there was a shortage of planners and installers. Teaching has been done on the job and especially the bigger institutions have been too late with offering appropriate programs and courses. On the technical side, systems have become standardized and simplified, and the required knowledge shifted from electrical engineering topics to the awareness of regulatory requirements and standards.

In many regions, certificates for students and teachers are important to award the successfully passed exams and to prove the technical and didactic skills of the local teachers. Concluding from all training activities abroad, it is essential to cope with cultural differences, to be ready to learn from one another and recognize technical discussions always as bi-directional know-how transfer.

\subsection{China}

The authors of this article have been involved in an exchange program funded by a Swiss platform REPIC (Renewable Energy \& Efficiency Promotion in International Cooperation) and the activities included introducing software-based teaching methodology in a teach-the-teacher scheme. Close and intensive collaboration has been established prior to the project start and was a pre-requisite for a successful project.

- First, it has to be recognized that the Chinese solar market is mature and - in particular in the solar thermal field - technical solutions as well as the value chain differ significantly from European standards. The software had to be extended to cover the systems typically installed in China.

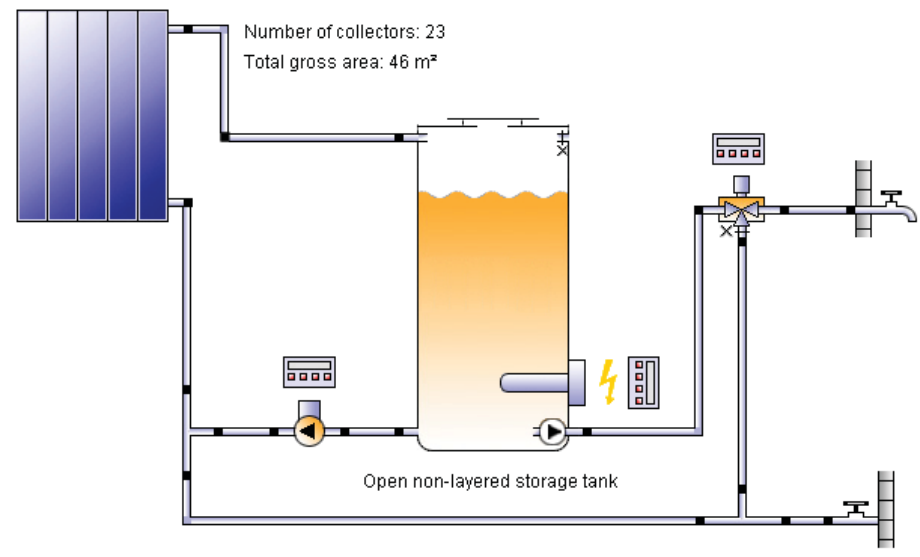

Figure 4: Typical Chinese system with open freshwater storage tank. Due to the strong circulation through the solar collector field, thermal stratification is destroyed deliberately. The tank is partially filled in times with low solar radiation, first fills up to $100 \%$ when more solar energy is available and heats up well above the required hot water temperature to increase energy storage capacity.

- Secondly, language was a major challenge since English has not been a common language between the European and the Chinese solar experts. Consecutive translation has been established for the know-how exchange and the simulation software graphical user interface has been translated into Chinese.

- Teaching methods have been adapted. As an example, the jigsaw exercise has proven to be very effective since it activated participants and trained technical expertise at the same time as teaching skills. Furthermore, it lowers language challenges when teachers and participants do not speak a common language since in jigsaw groups, Chinese-speaking participants teach their colleagues. 
Phase 1: expert groups
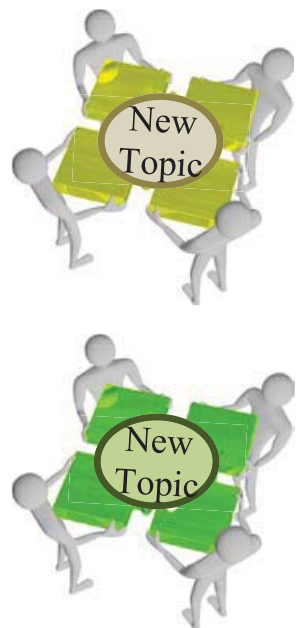
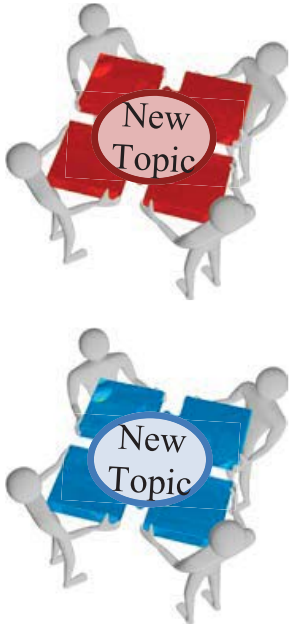

Phase 2: jigsaw groups

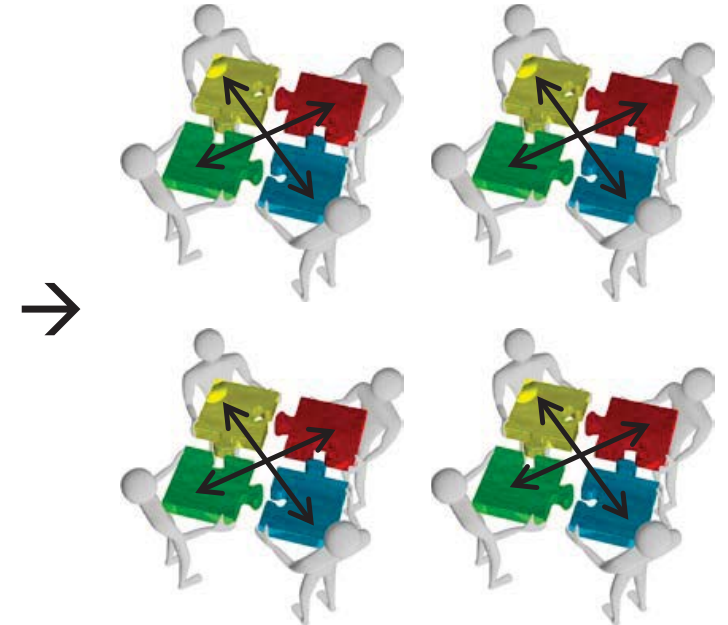

Figure 5: Jigsaw exercise. In a first round, small groups receive a new topic either by written or oral explanation. In a second round, groups are reorganized in order that participants teach each other. The jigsaw exercise proved to be a valuable didactic concept as an ice-breaker and to activate participants in teach-the-teacher courses.

\subsection{Egypt}

The teaching project in Egypt was supported by the EU Tempus Project SOLEDA and carried out by a large partner consortium of experts across the European Union (Khayet 2014). Simulation software only used a minor part of the budget but still played a significant role. To fulfil one of the requirements stated by the SOLEDA project plan, the Polysun graphical user interface has been translated into the Arab language, as shown in Figure 6. Furthermore, as a major contribution to the SOLEDA project, some general course content has been provided by the authors and extensive teach-the-teacher activities have been carried out at in different places in Egypt and Europe.

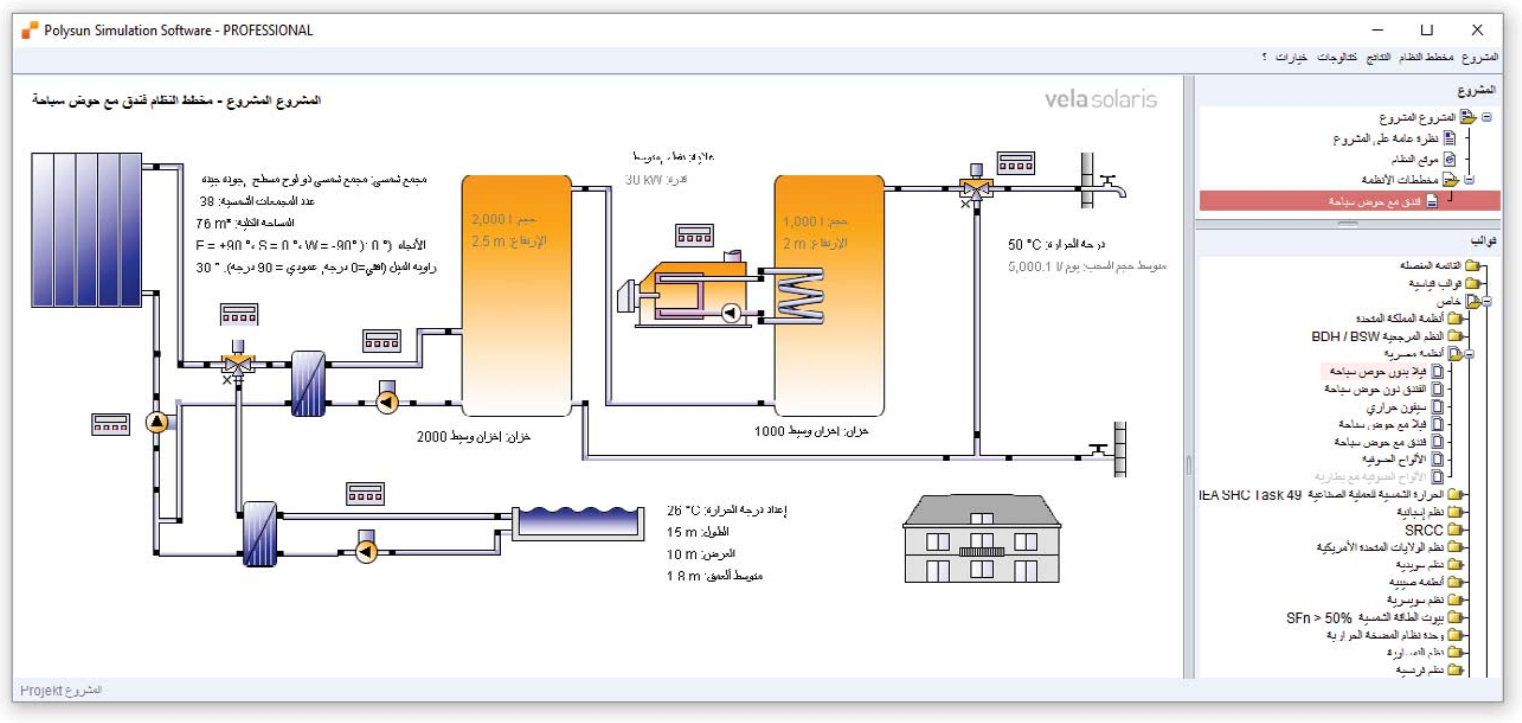

Figure 6: Polysun graphical user interface in the Arab language.

The project was running during a time of political change in Egypt. The positive attitude towards solar energy has been a constant source of motivation for all participants and also for the public (Soleda-Video 2016). Independent of political and economic boundary conditions, solar energy is a meaningful and high potential technology for Egypt and there is a shortage of skilled young professionals in this field. 


\subsection{Kuwait}

A long collaboration with the Kuwait Solar Energy for Private Training Institute (Al-Yaseen 2016) is worth mentioning because it shows how different various regions have to be treated in regards to solar education. Even though the simulation software is available in the Arab language, it is used in English. Furthermore, high quality training material is provided by the Institute, all with animated explanations and impressively rendered. The teacher is an accredited instructor and exams for participants are carried out in Kuwait. Quality assurance is partly supported by Vela Solaris in Switzerland and the certificates are in integral part of the training courses and represent a high value for participants.

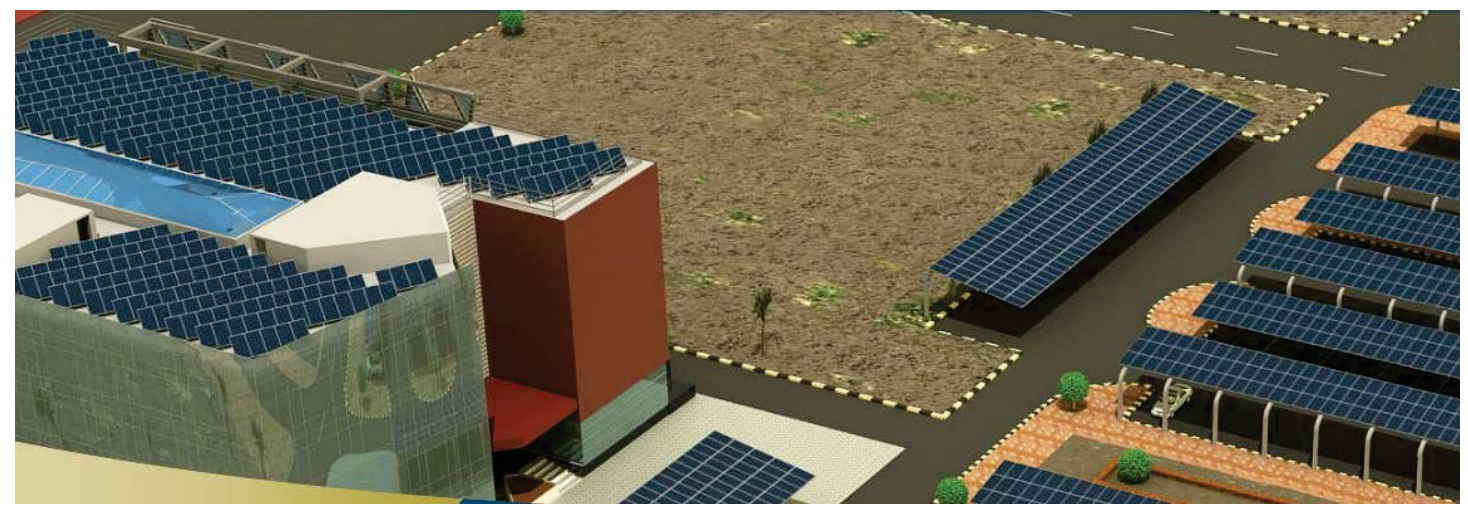

Figure 7: All teaching material is animated in high quality rendering.

\section{Conclusion and Outlook}

The authors have reported about experience with employing the simulation software Polysun in the educational context. The work spanned from supporting the curriculum of a new bachelor program to providing small learn objects that can be dealt with within a few lecture hours and can easily be shared between teachers. It has been found that simulation is useful to provide an understanding of data that is otherwise not accessible such as cumulated operating hours and number of starts of a heat pump depending on the control strategy. Consequently, students learn more and the solar and renewable energy topic becomes more tangible. Furthermore, the use of simulation software in teaching has a positive influence on the motivation and attitude of the students and the attractiveness of the courses. These benefits typically come with the costs of some additional effort in lecture preparation. Relieve from that additional burden could be found in building up a good system of sharing exercise material.

It is proposed to spend future work on studying the learning process when using simulation software in solar education and in measuring the effect size of these modern teaching methods. In particular, a measure should be found to estimate the attractiveness of solar education and the experience of a positive effect of using simulation software in renewable energy teaching should be quantified.

\section{References}

Andersen E., 2016, Application of Polysun at DTU Denmark. Publication in the Proceedings of SIGES, September 2016, Winterthur, Switzerland

Al-Yaseen A., Solar Energy and Polysun Simulation Software Certificate Course in Kuwait. Publication in the Proceedings of SIGES, September 2016, Winterthur, Switzerland

Bales C., Lorenz K., 2016, Application of Polysun in Teaching Courses in Sweden and in the PhD Program SHINE. Publication in the Proceedings of SIGES, September 2016, Winterthur, Switzerland 
Bony J., 2016, Application of Polysun in French speaking part of Switzerland. Publication in the Proceedings of SIGES, September 2016, Winterthur, Switzerland

Broman L., et al, 1991, A concentrated course in solar thermal process engineering. Proc of the ISES Solar World Congress, Denver, Colorado, Pergamon Press. 1991: 3815-3820

Canizares, C., Faur, Z., 1997, Advantages and Disadvantages of Using Various Computer Tools in Electrical Engineering Courses. IEEE Transactions on Education, vol. 40, no. 3, August 1997

Cook, A., et al., 2011, Technology-Enhanced Simulation for Health Professions Education A Systematic Review and Meta-analysis, Journal of the American Medical Association, issue 306, pp. 978-988

Edgar. T. F., et al., 2006, A global view of graduate process control education. Computers \& Chemical Engineering, issue 30, pp. 1763-1774

Feurzeig, W., Roberts, N, (1999), Modeling and Simulation in Science and Mathematical Education, Springer, New York, ISBN: 0-387-98316-3

Kandpal, T. C. \& Broman, L. (2015). Renewable energy education: a worldwide status review. Strömstad: Strömstad Akademi., ISBN: 9789186607302

Khayet, M., Ghannam R., and A. Khalil (2014). Solar energy system design using advanced learning aids (SOLEDA): an EU Tempus project. In the proceedings of the 8th International Technology, Education and Development Converence INTED-2014, pp2283-2291, March 2014, Valencia, Spain.

Milrad, M., et al., 2013, Seamless Learning: An International Perspective on Next Generation Technology Enhanced Learning. Chapter in Z. L. Berge \& L.Y. Muilenburg (eds.) Handbook of Mobile Learning.

Pillay, H., et al., 2006, Some Insights into the impact of ICTS on Learning Agency and Seamless Learning. Chapter in Cortelli, A. (ed.) Teaching in the knowledges society: New Skills and Instruments for teachers.

Prandini M., Best Practice Teaching Methods in a Teach-the-Teacher Program in China. Publication in the Proceedings of SIGES, September 2016, Winterthur, Switzerland

Rutten, N., et al., 2012, The learning effects of computer simulation in science education. Computers \& Education, Elsevier, issue 58, pp 136-153

Rumsey, D.J., 2000, Promoting student-centered learning in a studio classroom environment, ASA Stat. Ed. Section Newsletter, v. 6, http://www.stat.ncsu. edu/stated/newsletter/v6n2/studio.html (6 April, 2004).

Soleda-Video 2016. https://www.youtube.com/watch?v=B1a4RbROvuw, Cairo, Egypt.

Trey, L., Khan, S., How science students can learn about unobservable phenomena using computer-based analogies. Computing in Science \& Engineering, 10(5), pp 24-27.

Witzig, A., et al, 2009, Teaching Solar Thermal System Design by Use of Simulation Software. Publication in the Proceedings of ESTEC, May 2009, Munich, Germany.

Wolf A., Jiankun Z., et al., 2016, Renewable Energy Training and Certificate Program in China. Publication in the Proceedings of SIGES, September 2016, Winterthur, Switzerland 